\title{
A pilot study of low-dose erythromycin in bronchiectasis
}

\author{
K.W.T. Tsang*, P.-I. Ho**, K.-n. Chan ${ }^{+}$, M.S.M. Ip*, W.-k. Lam*, C.-s. Ho*, K.Y. Yuen**, G.C. Ooi ${ }^{++}$, \\ R. Amitani ${ }^{\S}$, E. Tanaka
}

A pilot study of low-dose erythromycin in bronchiectasis. K.W.T. Tsang, P.-l. Ho, K.-n. Chan, M.S.M. Ip, W.-k. Lam, C.-s. Ho, K.Y. Yuen, G.C. Ooi, R. Amitani, E. Tanaka. (C)ERS Journals Ltd 1999.

ABSTRACT: Patients with bronchiectasis suffer from sputum production, recurrent exacerbations, and progressive airway destruction. Erythromycin is effective in diffuse panbronchiolitis, another suppurative airway disorder, although its efficacy is unknown in idiopathic bronchiectasis.

A double-blind placebo-controlled study was therefore conducted to evaluate the effects of 8-week administration of low dose erythromycin (500 $\mathrm{mg}$ b.i.d.) in steadystate idiopathic bronchiectasis.

Patients in the erythromycin group $(n=11,8$ female, mean age $50 \pm 15$ yrs $)$, but not the placebo group $(\mathrm{n}=10,8$ female, mean age $59 \pm 16 \mathrm{yrs})$ had significantly improved forced expiratory vol-ume in one second, forced vital capacity and 24-h sputum volume after 8 weeks $(\mathbf{p}<\mathbf{0 . 0 5})$. There was no parallel improvement in sputum pathogens, leukocytes, interleukin (IL)-1 $\alpha$ and IL-8, tumour necrosis factor- $\alpha$, or leukotriene $B_{4}$.

The results of this pilot study show that low-dose erythromycin improves lung function and sputum volume in bronchiectasis. Further studies are indicated to evaluate the efficacy of long-term erythromycin therapy in bronchiectasis.

Eur Respir J 1999; 13: 361-364. Depts of $*$ Medicine, **Microbiology,
${ }^{+}$Paediatrics and ${ }^{++}$Radiology, The Uni-
versity of Hong Kong, Hong Kong. ${ }^{\S}$ Chest
Disease Research Institute, Kyoto Univer-
sity, Japan.

Correspondence: K.W.T. Tsang, University Dept of Medicine, The University of Hong Kong, Queen Mary Hospital, Pokfulam Road, Hong Kong, Fax: 852 28725828

Keywords: Bronchiectasis
cilia
cytokines
erythromycin
sputum

Received: November 51997

Accepted after revision September 261998

Supported by a CRCG grant of the University of Hong Kong.
Bronchiectasis is a common condition in the Chinese, and affected patients suffer from regular sputum production punctuated by recurrent infective exacerbations. Different pro-inflammatory mediators particularly interleukin (IL)-1, IL-8, and tumour necrosis factor (TNF)- $\alpha$, and leukotriene $\left(\mathrm{LT}^{-} \mathrm{B}_{4}[1-3]\right.$ contribute to mucus secretion and recruitment of neutrophils to the inflamed airways which degranulate and release harmful products such as neutrophil elastase $[4,5]$. Erythromycin (EM) is clinically effective in reducing sputum production in patients with bronchorrhoea [6] and diffuse panbronchiolitis (DPB) which, similar to bronchiectasis, is characterized by copious sputum production, rhinosinusitis, progressive airway destruction, and chronic Pseudomonas aeruginosa infection of the airways [7, 8]. Although low-dose EM is used frequently in the treatment of chronic bronchiectasis in Japan and many parts of Asia, the possible efficacy of EM in idiopathic bronchiectasis has not been studied in a controlled manner. This double-blind placebo-controlled pilot study was therefore performed to evaluate the effects of 8week administration of low-dose EM (500 mg b.i.d.) in steady-state bronchiectasis.

\section{Methods}

\section{Patient selection}

Patients with proven bronchiectasis, diagnosis by highresolution computed tomography (HRCT), were recruited from the outpatient clinics of the University of Hong Kong. Inclusion criteria included: $24-\mathrm{h}$ sputum volume $>10 \mathrm{~mL}$; absence of unstable systemic diseases; and "steady-state" bronchiectasis $(<10 \%$ alteration of 24 -h sputum volume, forced expiratory volume in one second (FEV1) and forced vital capacity (FVC), and in the absence of deterioration in cough, dyspnoea, wheezing, fever, or chest pain at baseline visits). Exclusion criteria included: unreliable clinic attendance, adverse reaction to macrolides, and females who were lactating. Written informed consent was obtained, and the study protocol had approval from the institutional ethics committee. Patients were assessed at 0 and 8 weeks after commencement of therapy.

\section{Clinical and laboratory assessment}

At each visit, each patient was examined fully. Laboratory assessment included: 24-h sputum volume, sputum leukocyte density (per $\mathrm{mL}$ ); sputum pathogenic density (colony forming unit (cfu) $\cdot \mathrm{mL}^{-1}$ ); and sputum (sol phase) IL- $1 \alpha$, TNF- $\alpha$ and LTB $_{4}$. Spirometry was measured between 10:00 and 11:00 h, using standard protocols, with a SensorMedics 2200 (SensorMedics, Yorba Linda, CA, USA) package. The number of bronchiectatic lung lobes was determined using thin-cut HRCT, within 12-months of the assessment in the supine position [9]. The aetiology of bronchiectasis was determined after history taking, examination, and investigations including nasal respiratory ciliary beat frequency assessment [10]. Evaluation of serum immunoglobulin (Ig)G, IgA, and IgM; auto antibody 
titres (for rheumatoid factor, anti-nuclear factor, and $\mathrm{IgG}$ against Ro, La, Jo- ${ }_{1}$, mitochondrial, and smooth muscle); serum IgG subclasses; $\alpha_{1}$-antitrypsin level; viral titres (measles, mumps, influenza, para-influenza, respiratory syncytial, adeno-, rota-, and entero-viruses); blood CD4/CD8 lymphocyte ratio; IgG against $P$. pseudomallei, Legionella pneumophilia, Chlamydia psittaci, and Mycoplasma pneumoniae; aspergillus precipitins; serum cold haemagglutinin; complements 3 and 4; and sputum microbiology (routine aerobic and anaerobic, mycobacterial and fungal cultures) was performed at the Biochemistry, Haematology, Clinical Immunology, and Microbiology Departments of the University of Hong Kong.

Sputum collection and assessment for physical characteristics

The methodology on sputum collection and assessment of 24-h sputum volume has been described previously [11]. Briefly, 24-h sputum collection was made at home in clear sterile plastic $(60-\mathrm{mL})$ pots, and fresh sputum was obtained within $1 \mathrm{~h}$ following $15 \mathrm{~min}$ of expectorationaiding physiotherapy (or until no further sputum was obtained). Sputum leukocyte density, performed on five randomly selected aliquots of a fresh specimen, was assessed within $2 \mathrm{~h}$ using light microscopy and haemocytometry [11].

\section{Sputum microbiology}

Standard microbiological and dilutional techniques were employed to identify all the sputum pathogens (P. aeruginosa, Haemophilus influenzae, Streptococcus pneumoniae, Staphylococcus aureus, and Gram-negative bacilli) and to determine their densities in sputum using enriched and selective media (blood agar (Oxoid CM271 (Oxoid, Basingstoke, UK), with 5\% defibrinated horse blood), chocolate agar supplemented with $18.9 \mathrm{U} \cdot \mathrm{mL}^{-1}$ bactracin (Sigma, St. Louis, MO, USA), mannitol salt agar (Oxoid CM85) and cetrimide-nalidixic acid agar (Oxoid CM559 and SR102)) incubated at $37^{\circ} \mathrm{C}$ in $5 \% \mathrm{CO}_{2}$ [11].

\section{Measurement of sputum pro-inflammatory cytokine and $\mathrm{LTB}_{4}$ concentrations}

Fresh sputum was stored at $-70^{\circ} \mathrm{C}$ within 15 min of collection until ultracentrifugation $(100,000 \times g$ for $30 \mathrm{~min}$ at $4^{\circ} \mathrm{C}$ ) was used to obtain the sol phase needed for enzymelinked immunoabsorbent assay of cytokine and $\mathrm{LTB}_{4}$ levels performed in commercially available 96-well plates (R\&D Systems, Minneapolis, MN, USA) [11]. The mean concentration of the cytokines or $\mathrm{LTB}_{4}$ was determined from triplicate measurements.

\section{Data analysis}

The primary objective of this study was to evaluate the effects of low-dose EM on sputum volume and lung function indices in steady-state bronchiectasis. Based on the authors' experience, the daily sputum volume might vary by as much as $10 \%$ between days in stable bronchiectatic patients. Accepting a type I error of 0.05 and a type II error of 0.20 (power 0.80 ), a study size for a randomized placebo-controlled study of 20 subjects (10 in each treatment group) would allow detection of $12 \%$ change in sputum volume. As the lung function, sputum volume and cytokine concentrations were log-normally distributed, they were logarithmically transformed before analysis. These variables were compared between treatment groups by analysis of variance (ANOVA) with Bonferroni's correction and reported as the geometric mean and $95 \%$ confident interval. Within-group changes after treatment were examined with paired Student's t-tests. Data that were highly skewed (sputum bacteriology and leukocyte density) were compared between and within treatment groups by Wilcoxon's rank sum test and reported as median and interquartile range. A p-value of $<0.05$ was taken as indicative of statistical significance.

\section{Results}

\section{Patient demography and clinical details}

The patient demography and clinical details are shown in table 1. Between October 1996 and April 1997, 14 and 10 patients, who suffered from idiopathic bronchiectasis, were recruited to receive EM (500 mg twice daily) and identical placebo tablets, respectively. In the EM group, three patients were withdrawn as two were unreliable attenders and one developed a maculopapular rash 5 days after EM therapy. The mean age and number of exacerbations in the previous 12 months were not significantly

Table 1. - Clinical characteristics of patients in the erythromycin and placebo groups at baseline

\begin{tabular}{lcc}
\hline & $\begin{array}{c}\text { Erythromycin } \\
\text { group } \\
(\mathrm{n}=11,8 \mathrm{~F})\end{array}$ & $\begin{array}{c}\text { Placebo } \\
\text { group } \\
(\mathrm{n}=10,8 \mathrm{~F})\end{array}$ \\
\hline Age yrs* & $50 \pm 15$ & $59 \pm 16$ \\
Smoking history & 10 & 8 \\
$\quad$ Never & 1 & 2 \\
Exsmokers & $2.1 \pm 1.68$ & $2.9 \pm 1.2$ \\
Number of exacerbations in & & \\
previous 12 months* & $3.0 \pm 1.34$ & $3.2 \pm 1.40$ \\
Number of lung lobes with & & \\
bronchiectasis* & 8 & 7 \\
Past medical history & 1 & 0 \\
Nil else & 1 & 0 \\
Thrombocytopaenia & 1 & 0 \\
Bone marrow transplant & 0 & 1 \\
Biliary calculi & 0 & 1 \\
Renal transplant & 0 & 1 \\
Hypertension & & \\
Hepatitis B & 6 & 6 \\
Current medications & 6 & 3 \\
Inhaled bronchodilators & 2 & 3 \\
Inhaled steroids & 1 & 0 \\
Nebulized aminoglycosides & 1 & 1 \\
Prednisolone & 1 & 0 \\
Cyclosporin & 0 & 1 \\
Azathioprine & & \\
Diuretic & &
\end{tabular}

Data are presented as number of patients, except where indicated. *: data are mean \pm SD. F: female. There was no significant difference between the age or number of exacerbations in the previous 12 months between the two groups $(\mathrm{p}>0.05)$. 
Table 2. - Spirometry, sputum characteristics and pro-inflammatory mediator levels before and after treatment in the patient groups

\begin{tabular}{|c|c|c|c|c|}
\hline & \multicolumn{2}{|c|}{ Erythromycin } & \multicolumn{2}{|c|}{ Placebo } \\
\hline & Before treatment & After treatment & Before treatment & After treatment \\
\hline $\begin{array}{l}\text { Forced expiratory volume in } \\
\text { one second L }\end{array}$ & $1.06(0.77-1.47)$ & $1.20(0.84-1.73)^{*}$ & $0.99(0.71-1.39)$ & $0.94(0.66-1.33)$ \\
\hline Forced vital capacity L & $1.85(1.35-2.53)$ & $1.97(1.38-2.79)^{*}$ & $1.51(1.17-1.94)$ & $1.51(1.14-2.00)$ \\
\hline 24-h volume $\mathrm{mL}$ & $33.7(23.0-49.3)$ & $23.8(15.7-36.1)^{*}$ & $26.2(18.4-37.4)$ & $22.7(16.0-32.3)$ \\
\hline $\begin{array}{l}\text { Bacterial density } \times 10^{7} \\
\text { cfu } \cdot \mathrm{mL}^{-1+}\end{array}$ & $1.93(1.08-5.04)$ & $3.84(2.20-7.40)$ & $7.66(0.48-13.4)$ & $1.85(0.95-3.48)$ \\
\hline $\begin{array}{l}\text { Commensal bacterial density } \\
\times 10^{7} \mathrm{cfu} \cdot \mathrm{mL}^{-1+}\end{array}$ & $0.94(0.39-2.84)$ & $1.99(0.80-2.45)$ & $2.41(0.20-5.00)$ & $1.05(0.30-2.86)$ \\
\hline $\begin{array}{l}\text { Pathogen density } \times 10^{7} \\
\mathrm{cfu} \cdot \mathrm{mL}^{-1+}\end{array}$ & $0.18(0.01-1.73)$ & $0.77(0.01-6.05)$ & $0.10(0.00-10.4)$ & $0.18(0.00-1.40)$ \\
\hline Leukocyte density $\times 10^{7} \cdot \mathrm{mL}^{-1+}$ & $0.73(0.36-10.0)$ & $1.26(0.17-8.50)$ & $6.76(0.97-9.50)$ & $2.68(0.87-12.1)$ \\
\hline Interleukin- $1 \alpha \mathrm{pg} \cdot \mathrm{mL}^{-1}$ & $6029(2440-14894)$ & 7395 (3114-17559) & $15152(6205-37001)$ & $15536(7047-34252)$ \\
\hline Interleukin-8 $\mathrm{pg} \cdot \mathrm{mL}^{-1}$ & $17648(7610-40929)$ & $20858(11646-37358)$ & $16196(7713-34006)$ & $18648(10843-32071)$ \\
\hline $\begin{array}{l}\text { Tumour necrosis factor- } \alpha \\
\mathrm{pg} \cdot \mathrm{mL}^{-1}\end{array}$ & $92.9(38.8-222.2)$ & $98.0(55.2-173.9)$ & $127.5(30.4-534.6)$ & $82.0(18.5-363.3)$ \\
\hline Leukotriene $\mathrm{B}_{4} \mathrm{pg} \cdot \mathrm{mL}^{-1}$ & $3090(992-9621)$ & $2190(720-6663)$ & $1547(834-2866)$ & $3309(1638-6684)$ \\
\hline
\end{tabular}

Data are presented as geometric mean with $95 \%$ confidence interval in parentheses, unless otherwise indicated. ${ }^{+}$: median (interquartile range). *: $\mathrm{p}<0.05$ when compared with baseline.

different at baseline between the two groups ( $\mathrm{p}>0.05)$. No other adverse reactions had been reported in either group. None of the patients in the EM group experienced haemoptysis or exacerbations, whereas two patients in the placebo group had an exacerbation during the "treatment phase" which resolved after 10 days' treatment with sparfloxacin (200 mg daily). No other alteration in regular medications was made during the study.

\section{Spirometry and sputum indices}

The spirometry and sputum indices results are shown in table 2. FEV1, FVC, and 24-h sputum volume improved significantly $(\mathrm{p}<0.05)$ in the EM group but not the placebo group. $P$. aeruginosa and $H$. influenzae were isolated from the sputum in, respectively, 10 and one of the EM patients, and $P$. aeruginosa, $H$. influenzue, Klebsiella pneumoniae, and Escherichia coli isolated in the sputum of six, two, one and one placebo patient, respectively. The sputum pathogenic densities and concentrations of IL- $1 \alpha$, IL-8, TNF- $\alpha$ and $\mathrm{LTB}_{4}$ did not change significantly in either group $(\mathrm{p}>0.05)$.

\section{Discussion}

The results of this study show that 8-week administration of low-dose EM significantly reduces sputum volume and improves lung function in steady-state severe idiopathic bronchiectasis. However, the in vitro parameters showed no significant changes including sputum densities of leukocytes, pro-inflammatory mediators, and pathogens. Not withstanding the small sample size and the short study duration, the EM group appeared to have less infective exacerbations than the placebo group. Despite the lack of statistical significance, the median values of sputum pathogenic and leukocyte densities appeared to have improved after 8 weeks of placebo treatment. This might have been related to the administration of antibiotics in two patients but might also have occurred by chance as a placebo effect.

There is considerable traffic of neutrophils migrating into the tracheobronchial wall which is probably the result of both host and bacterial factors [12]. Bacterial products induce production of IL- $1 \alpha$ and TNF- $\alpha$ which leads to expression of the chemoattractants intracellular adhesion molecule (ICAM)-1 and the CD11/CD18 integrin complex $[1,13]$. IL- 8 and $\mathrm{LTB}_{4}$ are potent chemoattractants and IL-8 may also degranulate neutrophils in the bronchiectatic airways $[2,5]$. This study, being one of the few longitudinal profiles of sputum pro-inflammatory mediators, showed a "static" output of inflammatory mediators after EM therapy. This might simply be a type II error or a reflection of a lack of response at the biochemical level. A previous study also showed that "clinically efficacious" treatment did not alter the levels of sputum IL-1 $\alpha$, IL- 8 , and TNF- $\alpha$ concentrations after antibiotic treatment which improved sputum purulence and volume in six bronchiectatic patients [14]. Similarly, sputum levels of IL-8, TNF$\alpha$, and ICAM-1 do not correlate with clinical status in cystic fibrosis $[15,16]$.

Low-dose EM treatment improves lung function and prevents disease progression in DPB, an idiopathic chronic suppurative airway disease predominantly seen in Japan. The present authors' extensive investigations [8] had excluded DPB in all the patients. The mechanism of action of EM in bronchiectasis is not known although it is unlikely to be bactericidal in view of the low dosage and poor tracheobronchial penetration. EM inhibits glycoconjugate release [17] and chloride secretion by airway epithelium [18], and macrophage mucus secretagogue production [19] which might result in decreased sputum water contents and volume. Low dose EM might also affect the bacterial-host interaction in vivo [20] by altering bacterial morphology and P. aeruginosa exotoxin production [21], neutrophil migration [22], superoxide generation [22], and macrophage production of mucus secretagogue [19]. 
The results of this preliminary study, which is the first controlled study on the effects of erythromycin in chronic bronchial sepsis, show the efficacy of low dose and moderately long-term administration of erythromycin in steadystate bronchiectasis. Low dose and long-term erythromycin therapy might be a disease modifying treatment for idiopathic bronchiectasis, and further studies should be performed to establish the dose response, appropriate duration of therapy, and criteria for patient selection.

\section{References}

1. Schleimer RP, Benenati SV, Friedman B, Bochner BS. Do cytokines play a role in leukocyte recruitment and activation in the lung? Am Rev Respir Dis 1991; 143: 11691174.

2. Baggiolini M, Walz A, Kunkel SL. Neutrophil-activating peptide-1/interleukin 8 , a novel cytokine that activates neutrophils. J Clin Invest 1989; 84: 1045-1049.

3. Oda $\mathrm{H}$, Kadota J, Kohno S, Hara K. Leukotriene $\mathrm{B}_{4}$ in bronchoalveolar lavage fluid of patients with diffuse panbronchiolitis. Chest 1995; 108: 116-122.

4. Lundgren JD, Shelhamer JH. Pathogenesis of airway mucus hypersecretion. J Allergy Clin Immunol 1990; 85: 399-417.

5. Amitani R, Wilson R, Rutman A, et al. Effects of human neutrophil elastase and bacterial proteinases on human respiratory epithelium. Am J Respir Cell Mol Biol 1991; 4: 26-32.

6. Marom ZM, Goswami SK. Respiratory mucus hypersecretion (bronchorrhea): a case discussion-possible mechanism(s) and treatment. J Allergy Clin Immunol 1991; 87: 1050-1055.

7. Kudoh S, Uetake T, Hagiwara K, et al. Clinical effects of low-dose, long-term erythromycin chemotherapy on diffuse panbronchiolitis. Jpn J Thorac Dis 1987; 25: 632642.

8. Tsang KWT, Ooi C, Tanaka E, et al. Diffuse panbronchiolitis in Chinese patients. Thorax 1998; 53: 274-280.

9. McGuniness G, Naidich DP, Leitman BS, McCauley DI. Bronchiectasis: CT evaluation. Am J Radiol 1993; 160 : 253-259.

10. Greenstone MA, Logan-Sinclair R, Cole PJ. An auto- mated methods of recording ciliary beat frequency. IRCS Med Sci 1984; 12: 715-716.

11. Tsang KW, Ho PL, Lam WK, et al. Inhaled fluticasone reduces sputum inflammatory indices in severe bronchiectasis. Am J Respir Crit Care Med 1998; 158: 723-727.

12. Ras G, Wilson R, Todd H, Taylor G, Cole PJ. Effect of bacterial products on neutrophil migration in vitro. Thorax 1990; 45: 276-280.

13. Wilmott RW, Kassab JT, Kilian PL, Benjamin WR, Douglas SD, Wood RE. Increased levels of interleukin-1 in bronchoalveolar washings from children with bacterial pulmonary infections. Am Rev Respir Dis 1990; 142: 365-368.

14. Eller J, Lapa E, Silva JR, Poulter LW, Lode H, Cole PJ. Cells and cytokines in chronic bronchial infection. Ann NY Academy of Sciences 1994; 725: 331-345.

15. Rochat T, Pastore FD, Schlegal-Haueter SE, et al. Aerosolized rhDNase in cystic fibrosis: effect on leucocyte proteases in sputum. Eur Respir J 1996; 9: 2200-2206.

16. Salva PS, Doyle NA, Graham L, Eigen H, Doerschuk CM. TNF $\alpha$, IL-8, soluble ICAM-1, and neutrophils in sputum of cystic fibrosis patients. Pediatr Pulmonol 1996; 21: 11-19.

17. Goswami SK, Kivity S, Marom Z. Erythromycin inhibits respiratory glycoconjugate secreteion from human airways in vitro. Am Rev Respir Dis 1990; 141: 72-78.

18. Tamaoki J, Isono K, Sakai N, Kanemura T, Konno K. Erythromysin inhibits chloride secretion across canine tracheal epithelial cells. Eur Respir J 1992; 5: 234-238.

19. Marom Z, Shelhamer JH, Kaliner M. Human pulmonary macrophage-derived mucus secretgogue. J Exp Med 1984; 159: 844-860.

20. Tsang KW, Rutman A, Kanthakumar K, et al. Haemophilus influenzae infection of human respiratory mucosa in low concentrations of antibiotics. Am Rev Respir Dis 1993; 148: 201-207.

21. Tanaka E, Kanthakumar K, Cundell DR, et al. The effects of erythromycin on Pseudomonas aeruginosa and neutrophil-mediated epithelial damage. J Antimicrob Chemother 1994; 33: 765-775.

22. Anderson R. Erythromycin and roxithromycin potentiate human neutrophil locomotion in vitro by inhibition of leukoattractant-activated superoxide generation and autooxidation. J Infect Dis 1989; 159: 966-973. 